\title{
$\nabla$ \\ Administration of Clonidine as Adjuvant to Infiltration Anaesthesia in Tympanoplasty Surgery
}

\section{IJCRR}

Section: Healthcare Sci. Journal Impact Factor: 6.1 (2018) ICV: 90.90 (2018)

Scopus'

\section{Ashok Chaudhari ${ }^{1}$, Amruta Mankar ${ }^{2}$, Pratibha Deshmukh ${ }^{3}$, Sweety Agrawal ${ }^{4}$}

Professor, Department of Anesthesia, Department of Anaesthesia, Jawaharlal Nehru Medical College, Datta Meghe Institute of Medical Sciences, Wardha, Maharashtra, India; 'Senior Resident, Department of Anaesthesia, Jawaharlal Nehru Medical College, Datta Meghe Institute of Medical Sciences, Wardha, Maharashtra, India; 3Professor and HOD, Department of Anesthesia Datta Meghe Medical College, Shalinitai Meghe Hospital and Research Centre Wanadongri, Nagpur-441110; ${ }^{4}$ Assistant Professor, Department of Anesthesia Datta Meghe Medical College, Shalinitai Meghe Hospital and Research Centre Wanadongri, Nagpur-441110.

\section{ABSTRACT}

Adjuvant to local anaesthesia increases the efficacy and the duration of the block. Inj Clonidine recently gaining more popularity as an adjuvant to local anaesthetic agents for neuraxial and peripheral nerve blocks. In this study, we compared two groups Lignocaine with adrenaline and lignocaine with clonidine in post auricular block in patients posted for tympanoplasty. 60 American Society of Anaesthesiologists ASA 1 and 2 patients posted for tympanoplasty were randomly allocated in 2 groups in which group A (control group) received $10 \mathrm{ml}$ solution of xylocaine with adrenaline (1:200,000 dilution) and $2 \mathrm{ml}$ of normal saline and group B (study group) received $10 \mathrm{ml}$ of adrenalized xylocaine with $30 \mathrm{mcg}$ of clonidine in $2 \mathrm{ml}$ of normal saline. Total volume of drug is similar in both the groups. Hemodynamic variables, oxygen saturation, level of analgesia were monitored in the intraoperative period. Incidence of postoperative nausea, vomiting, duration of analgesia, and other side effects was monitored till 24 hours after surgery. Duration of the block was significantly prolonged in group B. visual analog scale VAS scores were significantly lower at all times in group B as compared to group A. From this study we conclude that when $30 \mathrm{mcg}$ clonidine added to Xylocaine for post auricular nerve block proved to be more effective in providing analgesia introperatively and also postoperatively up to 6 hours. Interestingly the incidence of post-operative nausea vomiting was also lower in the clonidine group although it has no effect on the onset of analgesia.

Key Words: Ear surgeries, Hypotension, Ischemic heart disease, Diabetes mellitus, Bleeding disorder

\section{INTRODUCTION}

Clonidine was first introduced in 1966 under the brand name of CATAPRESS which initially was only used for the treatment of hypertension. The primary mechanism of action of clonidine is by sympatholysis by reducing the peripheral release of catecholamine through stimulation of the prejunctional inhibitory alpha 2 adrenoreceptors. Other uses of clonidine are based on its properties like sedative, anxiolytic and analgesic properties are being researched upon nowadays. Recent studies show that development of preservative-free clonidine can be safely used for neuraxial blocks ${ }^{1,2}$ but recently it's gaining more popularity as an adjuvant to local anaesthetic agents for neuraxial and peripheral nerve blocks. ${ }^{3,4}$

Local anaesthesia for middle ear surgery achieves better compliance, avoids unwanted complications, adequate sedation, and analgesia in intraoperative period and also it gives adequate postoperative analgesia. In our study, we have chosen inj. Clonidine to be administered with inj. Lignocaine in peripheral nerve block. ${ }^{17}$ Studies stating comparison between local versus general anaesthesia for middle ear surgeries have been conducted stating the advantages and disadvantages of both the techniques. ${ }^{5}$

Alpha agonist drugs when injected along axons had been shown to increase the efficacy of local anaesthetic drugs and thereby improving nerve block characteristics resulting in local vasoconstriction and facilitating $\mathrm{C}$ fibre block via local anaesthetic drug ${ }^{6,7}$. Although there was no evidence of neurotoxicity in humans, the current concern of using clonidine in regional anaesthesia is related to its haemodynamic and undesired sedative side effects. In a recent review and metaanalysis of perineural use of clonidine along with LA agents, clonidine prolonged mean duration of analgesia and motor blockade by about two hours and was associated with a high

\section{Corresponding Author:}

Dr. Amruta Mankar, Senior Resident, Department of Anaesthesia, Jawaharlal Nehru Medical College, Datta Meghe Institute of Medical Sciences, Wardha, Maharashtra, India; Email: amrutamankar11@gmail.com

ISSN: 2231-2196 (Print)

ISSN: 0975-5241 (Online)

Received: 15.05 .2020

Revised: 08.06 .2020

Accepted: 15.06 .2020

Published: 21.07 .2020 
incidence of hypotension with unclear dose responsiveness for beneficial or harmful effects. ${ }^{8}$

\section{METHODOLOGY}

The present study was conducted at Jawaharlal Nehru Medical College, AVBRH Hospital, Sawangi, Wardha during the period of April 2015 - January 2017 with due institutional ethical committee approval. A proper written informed consent was obtained from 60 ASA physical status I and II patients between the age group of 18-60 years of both genders posted for tympanoplasty surgery.

Patients suffering from chronic systemic disease including hypertension, ischemic heart disease, diabetes mellitus, bleeding disorder, local infection at the site of injection and patients refusal, patients receiving antiplatelet \& anti-coagulant medication were excluded from the study.

Patients were randomly allocated in 2 groups. Group A (control group) receiving $10 \mathrm{ml}$ solution of xylocaine with adrenaline (1:200,000 dilution) \& $2 \mathrm{ml}$ of normal saline and Group $\mathrm{B}$ (study group) receiving $10 \mathrm{ml}$ of xylocaine with adrenaline (1:200,000 dilution) with $30 \mathrm{mcg}$ of clonidine. Randomization and preparation of the drug were done by trained OT assistant not involved in the study. Standard guidelines of fasting were followed. The surgeon and anaesthesiologist involved in the study were not made aware of the patients included in the study group. We chose the standard technique of block administration by the same surgeon which provided a reliable distribution. Post auricular region and four quadrants of external auditory canal were infiltrated by the surgeon during the block. The absence of response to painful stimuli at the surgical site indicated that the block was effective following which the surgery was started.

Pre-operative patients were not given analgesic and sedative as it may interfere our study. Patient was monitored with ECG, oxygen saturation and non-invasive blood pressure monitoring, and EtCO2. Baseline haemodynamic parameters were noted, followed by those after giving the block, start of surgery, and every 10 min subsequently till the end of surgical procedure. After preparing the part, post auricular and endomeatal block was given by the surgeon with the aboveprepared solutions. Block was considered to be effective if the patient did not respond to the painful stimuli at the surgical site following which surgery was started. Patients were given oxygen through nasal prongs. Short-acting Sedation (injection midazolam $0.5-1 \mathrm{mg}$ ) and analgesia (injection fentanyl $25 \mathrm{mcg}$ to $50 \mathrm{mcg}$ ) was supplemented by anesthetists only when the patient complained of pain. Time to onset of analgesia, total duration of analgesia and hemodynamic parameter were assessed. Onset of analgesia was tested as loss of sensation to pinprick in the retro auricular area. The total duration of analgesia was taken to be from the institu- tion of the block to time of first analgesic dose. The duration of surgery was defined as the period between the time of incision to the time of the last suture. After the operation patients were observed for 24 hours. Analgesia was assessed using a standard 10 point visual analogue scale (VAS). This pain score was explained to the patients preoperatively by the anesthesiologist, and was assessed by a trained staff nurse who was unaware of the drug being given. Pain score of zero to 3 was taken as no pain whereas score more than 3 was taken as the patient was having pain and required rescue analgesia.

Side effects like hypotension, bradycardia, sedation, incidence of postoperative nausea, and vomiting were noted.

Demographic data and perioperative data are summarized as mean \pm S.D., Statistical analysis for significance was done by using two sample unpaired t-Test. Non parametric data were analyzed using Chi-square test. Pain scores were analyzed using Mann-Whitney Rank Sum test. A p-value of $<$ 0.05 was considered as statistically significant.

\section{RESULTS}

There were a total 60 number of patients included in the study. The demographic data and duration of surgery were comparable in both the groups ( $p>0.05$ ) showed no significant difference as shown in table no 1.

\section{Table 1: Demographic Data}

\begin{tabular}{llccc} 
Sr & Parameter & Group A & Group B & P value \\
No. & & & & \\
& Age & $33.03+12.56$ & $37.33+15.26$ & \\
Sex (M:F) & $13: 17$ & $10: 20$ & \\
Duration of & $120.32+16.36$ & $106.25+13.88$ & 0.3812 \\
Surgery & & & \\
ASA (1/2) & $17 / 13$ & $23 / 7$ & \\
\hline
\end{tabular}

Table 1 shows the demographic data and duration of surgery were comparable in both the groups $(p>0.05)$ showed no significant difference.

Haemodynamically parameters like pulse rate, SBP, DBP mean blood pressure (MAP) between the two groups was not statistically significant as shown in table 2 .

Block characteristics analysis showed no difference in the time of onset of sensory block (group A $98.2 \pm 20.39$ seconds vs group B $104 \pm 15.56$ seconds p value 0.15 ). In contrast, there was a significant difference in the duration of analgesia in both the groups. (Group A $134.4 \pm 26.05$ minutes VS $391.82 \pm 68.2$ minutes p-value 0.000009). During the first hour of post-operative period the mean pain score in both the groups were not significant. Analysis of pain scores reflected a significantly lower mean pain score in group B 
when compared to group A at the second hour (3.7 in group $\mathrm{A}$ and 1.49 in group $\mathrm{B}, \mathrm{p}<0.001)$. During subsequent hours although mean pain scores remained lower in the clonidine group, the difference in both groups was not significant statistically. The mean pain was lower in clonidine group than in the control group except for 6th post operative hour as shown in Diagram 1. The mean pain score increases briskly in control group at the end of 2 nd postoperative period. Four patients in group A had no pain while 26 patients had pain that needed systemic analgesic injection diclofenac 75 mg intravenous. In clonidine group, 12 patients had no pain while 18 patients had pain whom needed systemic analgesic drug at the 6th hour of postoperative period.

Table 2: Perioperative parameters

\begin{tabular}{|c|c|c|c|c|}
\hline $\begin{array}{l}\text { Sr } \\
\text { No. }\end{array}$ & Parameter & Group A & GROUP B & $\begin{array}{l}\text { P value } \\
\text { (T Test) }\end{array}$ \\
\hline 1 & $\begin{array}{l}\text { Onset of } \\
\text { Analgesia } \\
\text { (Seconds) }\end{array}$ & $98.2 \pm 20.39$ & $104.6 \pm 15 \cdot 56$ & 0.1514 \\
\hline 2 & $\begin{array}{l}\text { Mean Pulse } \\
\text { Rate }\end{array}$ & $80.63 \pm 18.21$ & $74.83 \pm 7.48$ & 0.5702 \\
\hline 3 & $\begin{array}{l}\text { Mean SBP } \\
(\mathrm{MMHG})\end{array}$ & $130.16 \pm 7.50$ & $118.9 \pm 5 \cdot 34$ & 0.0755 \\
\hline 4 & $\begin{array}{l}\text { Mean DBP } \\
(\mathrm{MMHG})\end{array}$ & $86.53 \pm 9.94$ & $76.86 \pm 6.72$ & 0.34 \\
\hline 5 & $\begin{array}{l}\text { Mean Arte- } \\
\text { rial Pressure } \\
(\mathrm{MMHG})\end{array}$ & $102.74 \pm 6.52$ & $90.87 \pm 5.36$ & 0.34 \\
\hline 6 & $\begin{array}{l}\text { Total } \\
\text { Duration of } \\
\text { Analgesia } \\
\text { (MINUTES) }\end{array}$ & $134.4 \pm 26.05$ & $391.82 \pm 68.2$ & $0.0000095^{2}$ \\
\hline 7 & $\begin{array}{l}\text { Sedation and } \\
\text { Analgesia } \\
\text { Required } \\
\text { During Intra } \\
\text { Operative } \\
\text { Period }\end{array}$ & 2 & none & \\
\hline
\end{tabular}

Table 2 showing intraoperative hemodynamic parameter (pulse rate, SBP, DBP mean blood pressure) between the two groups were not statistically significant. Onset of analgesia was not significant in both groups while total duration of analgesia was statistically significant in both groups.

Table 3: Assessment of quality of analgesia

\begin{tabular}{lll} 
Pain Score & Intensity of Pain & Quality of Analgesia \\
$0-3$ & No Pain & $\begin{array}{l}\text { Good (Not Requiring } \\
\text { Analgesia) }\end{array}$ \\
$>3-6$ & Mild Pain & $\begin{array}{l}\text { Fair (Requiring Analge- } \\
\text { sia) }\end{array}$ \\
$>6-10$ & Severe Pain & $\begin{array}{l}\text { Poor (Requiring Anal- } \\
\text { gesia) }\end{array}$ \\
\hline
\end{tabular}

Table 3 Showing Quality of Analgesia According to Vas Score. VAS is a subjective major of pain.

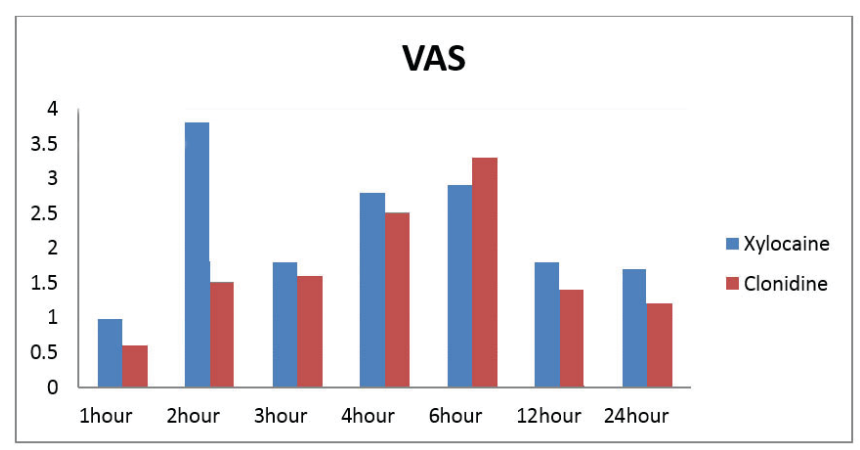

Diagram 1: Visual analogue scale.

Diagram no 1 indicates the analysis of pain scores reflected a significantly lower mean pain score in group B when compared to group $A$ at second hour (3.7 in group $A$ and 1.49 in group $\mathbf{B}$, p-value $\mathbf{0 . 0 0 2 2 5 1}$ ). Also, the duration of analgesia was enhanced by 2 hours of LA. In clonidine group analgesic requirement was at the 6th post operative hour where pain score was $>3$ which was statistically not significant.

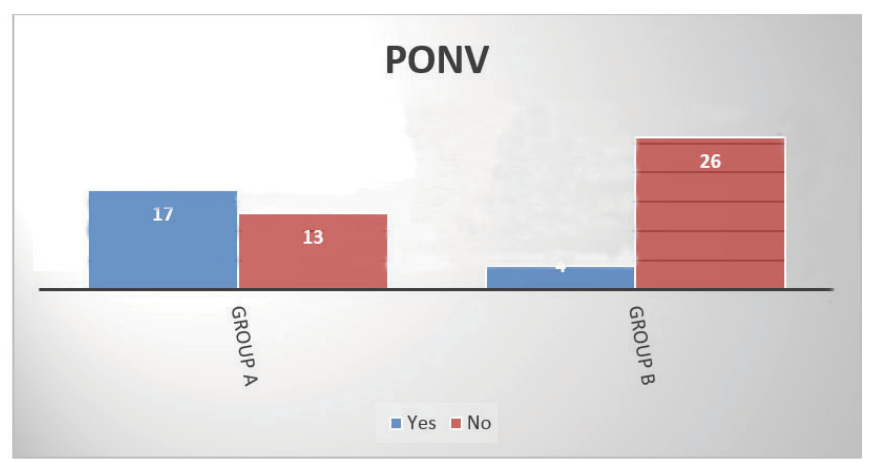

Diagram 2: Post Operative Nausea and Vomiting.

Figure 2 showing percentage of nausea vomiting in group A and group B. In group A 17 patients (57\%) had nausea and vomiting while in group B 4 patients (13.5\%) had nausea and vomiting.

Incidence of nausea and vomiting was higher in group A patients $17(57 \%)$ in compared to group B $4(13.33 \%)$ patients, which is statistically significant p-value 0.0000434 .

Bradycardia during surgical procedure observed in two patients with clonidine groups was managed by intravenous injection Atropin $0.6 \mathrm{mg}$. One patient in clonidine group had hypotension (SBP $<80 \mathrm{MMHG}$ ) which was managed by giving IV fluids. Patients and surgeons were comfortable throughout the procedure. 


\section{DISCUSSION}

In a well-conducted randomized clinical trials, alpha-2- agonists have been shown to be effective for their analgesic, sedative-hypnotic, as well as sympatholytic properties. As such, this class of agent has been shown to reduce intraoperative and postoperative stress response effectively. The benefit of adding clonidine to LAs for peripheral nerve blocks is less clear, although it is widely believed that clonidine improves quality as well as the duration of a LA block. The beneficial effect of clonidine in extending duration of peripheral nerve blocks is believed as a locally mediated effect, which is not reproduced by systemically administered clonidine. ${ }^{9-10}$ In this study, we decided to see the effects of clonidine in the infiltration block. It has been found in other studies that clonidine has a synergistic action with lignocaine resulting in prolonged duration of peripheral nerve block as it has enhancing effect on lignocaine induced inhibition of $\mathrm{C}$ fibre action potential. ${ }^{11}$

In one of the studies, clonidine without LA given through an interscalene catheter provided better analgesia compared with the systemic administration of the same dose. ${ }^{12}$. Another study by Gaumann DM et al. examined local anesthetic effects of clonidine and its interaction with lidocaine with regard to tonic inhibition of the C-fiber action potential (AP) on the isolated, desheathed rabbit vagus nerve by the sucrose gap method. The enhancing effect of a low dose of clonidine $(500 \mathrm{nM})$ on lidocaine-induced (500 microM) inhibition of C-fiber AP might explain the clinical observation that clonidine, at approximately 1000 -fold lower concentrations than lidocaine, prolongs the action of lidocaine in peripheral nerve block ${ }^{6}$.

A study done by Jayant Nick Pratap et al. by the addition of clonidine to local anesthesia prolongs the local anesthetic action, but in humans, the contribution of a peripheral mechanism remains unclear. They investigated clonidine's peripheral effect in 20 healthy volunteers undergoing double-blind, subcutaneous infiltration of $0.5 \%$ lidocaine with normal saline to one forearm and then, immediately, of lidocaine with $10 \mathrm{mcg}$ clonidine to the contralateral arm. Pinprick sensation was tested every $15 \mathrm{~min}$ for $6 \mathrm{~h}$. They concluded their study with the result that Median time to return of normal sensation was $3.5 \mathrm{~h}$ for lidocaine alone, but at least $6 \mathrm{~h}$ if combined with Clonidine (P 0.001) and that clonidine has a significant peripheral action in enhancing the duration of local anesthesia on superficial co-infiltration with lidocaine. Although clonidine might have a vasoconstrictive effect in large concentrations, the role of vasoconstriction in prolonging sensory block seems to be minor, even in usual clinical doses $(1-2 \mathrm{lg} / \mathrm{kg})^{13}$

In our study, the mean pain score was statistically improved in group B where clonidine was added as compared to group A. Two patients in group A and none in group B required supplementation of sedation and analgesia in the intraoperative period.

A dose of $30 \mathrm{mcg}$ of clonidine was used as a single dose peripheral nerve block. The minimum dose of clonidine to significantly prolong the duration of both anaesthesia and analgesia is $0.5 \mathrm{mcg} / \mathrm{kg}$ in the previous study conducted by Singelyn FS et al. ${ }^{14}$. Hence we have selected $30 \mathrm{mcg}$ of clonidine in this study.

Another important observation in our study was based on post-operative nausea and vomiting which interestingly was found to be lower in patients of group B. It was thought mainly to be due to the systemic action of clonidine which had significant anti-emetic action when given as a pre-medication orally in middle ear surgeries ${ }^{15}$ and strabismus surgeries ${ }^{16}$ In our study, clonidine was given as an infiltration block but its systemic absorption and subsequent action may have been manifested in the post-operative period resulting in decreased incidence of nausea and vomiting. The mechanism of action of clonidine as sympatholytic in addition to suppression of catecholamine release may be a contributing factor to this observation.

\section{CONCLUSION}

From this study, we conclude that when $30 \mathrm{mcg}$ clonidine added to xylocaine with adrenaline(1:200,000 dilution) for post auricular nerve block in patients posted for tympanoplasty proved to be more effective in providing analgesia intraoperatively and also postoperatively upto 6 hours. Clonidine adjuvant to local anaethetics enhances analgesic action of LA by 2 hours. Post-operative nausea vomiting incidence was also lower in the clonidine group. Thus, clonidine provides better patient compliance and better analgesia.

\section{Recommendation}

1. From the above study, we recommend the dose of 30 mcg clonidine as adjuvant to local anesthetic xylocaine with adrenaline for infiltration block in tympanoplasty surgery as patient compliance was good and surgeons were also comfortable.

2. This infiltration block with clonidine can be used to avoid general anesthesia in patients with comorbidities as a safe technique.

\section{Limitation of the study}

1. We may need to increase the sample size.

2. The same applies to the incidence of complications.

3. In this study ASA 3 and ASA 4 patient were not taken in to the consideration.

Acknowledgement: Authors acknowledge the immense help received from management of Datta Meghe Institute of Medical Sciences, Sawangi, India for providing support to conduct this study. 


\section{Conflicts of Interest: Nil}

Source of Funding: Nil

\section{REFERENCES}

1. Moss J, Glick D. The Autonomic Nervous System.In: Miller RD Editor. Miller's Anesthesia. 6th Ed. Philadelphia:Elsevier Churchill Livingstone 2005: 61777.

2. Sia S, Lepri A. Clonidine administered as an axillary block does not affect postoperative pain when given as the sole analgesic. Anesth Analg 1999; 88:1109-12.

3. Casati A, Magistris L, Fanelli G, Beccaria P, Cappelleri G, Aldegheri G, et al. Small-dose clonidine prolongs postoperative analgesia after sciatic-femoral nerve block with $0.75 \%$ ropivacaine for foot surgery. Anesth Analg 2000;91:388-92. 8.

4. Hutschala D, Mascher H, Schmetterer L, Klimscha W, Fleck T, Eichler HG, et al. Clonidine added to bupivacaine enhances and prolongs analgesia after brachial plexus block via a local mechanism in healthy volunteers. Eur J Anaesthesiol 2004;21:198204.

5. Mirko T (1993) Manual of middle ear surgery, 1st edn. Thieme, New York, pp 7-10.

6. Gaummann DM, Forster A, Griessen M, et al. Comparison between clonidine and epinephrine admixture to lidocaine in brachial plexus block. Anesth Analg 1992;75:69-74.

7. Gaumann DM, Brunet PC, Jirounek P. Hyperpolarizing afterpotentials in $\mathrm{C}$ fibers and local anesthetic effects of clonidine and lidocaine. Pharmacology 1994;48:21-9.

8. Pöpping DM, Elia N, Marret E, Wenk M, Tramèr MR. Clonidine as an adjuvant to local anesthetics for peripheral nerve and plex- us blocks: A meta-analysis of randomized trials. Anesthesiology 2009;111:406-15.

9. Nishikawa T, Dohi S (1990) Clinical evaluation of clonidine added to lidocaine solution for epidural anesthesia. Anesthesiology 73:853-859.

10. Singelyn FJ, Dangoisse M, Bartholomee S, Gouverneur JM (1992) Adding clonidine to mepivacaine prolongs the duration of anaesthesia and analgesia after axillary plexus block. Reg Anaesth 17:148-150.

11. Gaumann DM, Brunet PC, Jirounek P (1992) Clonidine enhances the effects of lidocaine on C-fibre action potential. Anesth Analg 74:719-725.

12. Iskandar H, Benard A, Ruel-Raymond J, Cochard G, Manaud B: The analgesic effect of interscalene block using clonidine as an analgesic for shoulder arthroscopy. Anesth Analg 2003; 96:260-2.

13. Acalovschi I, Bodolea C, Manoiu C (1997) Spinal anesthesia with meperidine: effects of added alpha-adrenergic agonistsepinephrine versus clonidine. Anesth Analg 84:1333-1339.

14. Singelyn FJ, Gouverneur JM, Robert A (1996) A minimum dose of clonidine added to mepivacaine prolongs the duration of anaesthesia and analgesia after axillary brachial plexus block. Anesth Analg 83:1046-1050.

15. Taheri A, Javadimaesh MA, Ashraf H (2010) The effect of oral clonidine premedication on nausea and vomiting after ear surgery. Middle East J Anesthesiol 20:691-694.

16. Mikawa K, Nishina K, Maekawa N, Asano M, Obara H (1995) Oral clonidine premedication reduces vomiting in children after strabismus surgery. Can J Anaesth 42(11):981-997.

17. Raghuvanshi SK, Chakravarty N, Asati D,Bankwar V. Use of clonidine as an adjuvant to infiltration anaesthesia in tympanoplasty: a randomized double blind st Indian J Otolaryngol Head Neck Surg. 2014 Jan;66(1):57-62. 